\title{
Nischarin attenuates apoptosis induced by oxidative stress in PC12 cells
}

\author{
ZHANPENG GUO ${ }^{1}$, YAJIANG YUAN ${ }^{1}$, YUE GUO $^{1}$, HONGYU WANG $^{1}$, CHANGWEI SONG ${ }^{1}$ and MINA HUANG $^{2}$ \\ ${ }^{1}$ Department of Orthopedics, The First Affiliated Hospital of Jinzhou Medical University; \\ ${ }^{2}$ Department of Nursing, Jinzhou Medical University, Jinzhou, Liaoning 121001, P.R. China
}

Received April 9, 2018; Accepted October 19, 2018

DOI: $10.3892 / \mathrm{etm} .2018 .7017$

\begin{abstract}
Nischarin (NISCH) is a cytoplasmic protein known to serve an inhibitory role in breast cancer cell apoptosis, migration and invasion. Recently, NISCH has been reported to be involved in the regulation of spinal cord injury (SCI). However, the molecular mechanism is still unclear. Oxidative stress contributes to tissue injury and cell apoptosis during the development of various diseases, including SCI. The aim of the present study was to investigate the role of NISCH in the regulation of apoptosis induced by oxidative stress in PC12 cells. $\mathrm{H}_{2} \mathrm{O}_{2}$ was used to establish an oxidative stress model in PC12 cells. Apoptosis levels were examined using flow cytometry analysis, and the expression of $\mathrm{NISCH}, \mathrm{Bcl}-2, \mathrm{Bcl}-2$-associated $\mathrm{X}(\mathrm{Bax})$ and caspase- 3 were examined using western blot and immunofluorescence staining analyses. The results demonstrated that treatment with $100 \mu \mathrm{M} \mathrm{H}_{2} \mathrm{O}_{2}$ significantly increased the apoptotic rate and expression of NISCH in PC12 cells. At $48 \mathrm{~h}$ following incubation with $100 \mu \mathrm{M} \mathrm{H}_{2} \mathrm{O}_{2}$, NISCH downregulation partially inhibited apoptosis of PC12 cells. In addition, the expression of Bcl-2 was significantly reduced and the expression of Bax and caspase- 3 were significantly increased by $\mathrm{H}_{2} \mathrm{O}_{2}$ treatment. These effects were also partially inhibited by the downregulation of NISCH. The authors of the present study therefore hypothesize that NISCH may function as a pro-apoptotic protein that participates in the regulation of oxidative stress, and NISCH downregulation may protect cells from oxidative stress-induced apoptosis.
\end{abstract}

\section{Introduction}

Spinal cord injury (SCI) occurs as a result of a multifactorial process, involving primary injury subsequently followed by a secondary injury (1). Primary injury, caused by an initial

Correspondence to: Dr Mina Huang, Department of Nursing, Jinzhou Medical University, 40 Songpo Road, Jinzhou, Liaoning 121001, P.R. China

E-mail: huangshumin1982@163.com

Key words: nischarin, hydrogen peroxide, oxidative stress, apoptosis, Bcl-2/Bcl-2-associated $\mathrm{X}$ signaling physical impact, is characterized by acute bleeding and ischemia (2). Secondary injury may be induced by several mechanisms, including inflammation, oxidative stress, ion balance dysregulation and excitotoxicity (3-5). It has been reported that allicin may protect rats against SCI via regulation of oxidative stress and inflammatory response pathways (6), while inhibition of reactive oxygen species (ROS) production may improve outcomes following SCI by mediating acute reductions in oxidative stress and inflammation (7). Apoptosis has been suggested as a potential therapeutic target for secondary SCI (8), as one of the most damaging processes of secondary SCI is neuronal apoptosis (9). Motor neuron apoptosis is the main cause of dysfunction following SCI, as it is one of the primary obstacles for locomotor functional recovery (10).

The generation of ROS, such as superoxide anions, $\mathrm{H}_{2} \mathrm{O}_{2}$ and hydroxyl radicals, is a normative response to disease or injury, including SCI (11). The increased formation of ROS may exceed the capacity of the antioxidant defense systems and subsequently lead to oxidative stress $(12,13)$. Oxidative stress serves an important role in apoptosis induction under physiologic and pathologic conditions $(14,15)$. A previous study demonstrated that myricetin may protect cells against $\mathrm{H}_{2} \mathrm{O}_{2}$-induced cell damage via its anti-apoptotic effects (16).

Nischarin (NISCH) is a cytosolic protein that is found anchored to the inner layer of the plasma membrane, and has been demonstrated to interact with cytosolic and intermembrane proteins (17). NISCH is expressed in various organs, and a previous study demonstrated that NISCH serves an inhibitory role in cell migration, invasion and the carcinogenesis of breast cancer cells (18). NISCH is highly expressed in the brain of adult rats, and has been confirmed to be expressed in PC12 and Neuro-2A cell lines (19). It has been reported that overexpression of NISCH may induce human breast cancer apoptosis and inhibit cell migration and invasion (20), while inhibition of NISCH expression promotes neurite outgrowth (18). Recently, it has been shown that NISCH downregulation by small-interfering RNA (siRNA) accelerates rat motor function recovery following SCI (21), indicating that NISCH may be involved in the pathological mechanisms of SCI. However, the exact molecular mechanism remains unclear.

The authors of the present study hypothesized that NISCH downregulation attenuates oxidative stress-induced apoptosis in PC12 cells. Therefore, the apoptotic rate of PC12 cells and 
the expression of $\mathrm{Bcl}-2 / \mathrm{Bcl}-2$-associated $\mathrm{X}$ (Bax) signaling pathway members was examined in the present study.

\section{Materials and methods}

Cell culture. The PC12 rat pheochromocytoma tumor cell line was purchased from PeproTech Inc. (Rocky Hill, NJ, USA) and maintained in RPMI 1640 medium supplemented with $10 \%$ heat-inactivated fetal bovine serum (both Gibco; Thermo Fisher Scientific, Inc., Waltham, MA, USA) and 100 U/ml penicillin and $100 \mu \mathrm{g} / \mathrm{ml}$ streptomycin (Thermo Fisher Scientific, Inc.) at $37^{\circ} \mathrm{C}$ in a humidified atmosphere containing $5 \% \mathrm{CO}_{2}$.

Flow cytometric analysis of cell apoptosis. Cells were treated with $100 \mu \mathrm{M} \mathrm{H}_{2} \mathrm{O}_{2}$ for $0,24,48,72$ and $96 \mathrm{~h}$. Following $\mathrm{H}_{2} \mathrm{O}_{2}$ treatment, cells were harvested by trypsinization and washed twice with cold phosphate-buffered saline (PBS). Cell apoptosis was measured following drug treatment using the Annexin V-FITC/PI Apoptosis Detection kit (Nanjing KeyGen Biotech Co., Ltd., Nanjing, China) according to the manufacturer's instructions. Cells were resuspended and mixed with $500 \mu \mathrm{l}$ binding buffer containing $5 \mu 1$ Annexin V-fluorescein isothiocyanate (FITC) and $5 \mu \mathrm{l}$ propidium iodide (PI). Following incubation for $15 \mathrm{~min}$ at room temperature in the dark, cell apoptosis was detected using fluorescence-activated cell sorting (FACS) flow cytometers from BD Biosciences (Franklin Lakes, NJ, USA) or Beckman Coulter, Inc. (Brea, CA, USA) using BD Cell Quest research software (version 5.2.1; BD Biosciences).

NISCH siRNA preparation and cell transfection. The NISCH siRNA and negative control sequences were as follows: $\mathrm{NISCH}$ siRNA sense, 5'-GCAAGCACUGACCACUCUATT-3' and anti-sense, 5'-UAGAGUGGUCAGUGCUUGCTT-3'; Negative control sense, 5'-UUCUCCGAACGUGUCACGUTT-3', and anti-sense, 5'-ACGUGACACGUUCGGAGAATT-3'. NISCH siRNA was diluted to $20 \mu \mathrm{M}$ with a universal buffer (Beijing Huaxia Ocean Technology Co., Ltd., Beijing, China). Cells were divided into control, vehicle and NISCH-siRNA groups. PC12 cells in the logarithmic growth phase were seeded at a density of $2.5 \times 10^{5}$ cells/well in a 12-well plate $(1 \mathrm{ml} /$ well $)$ and incubated at $37^{\circ} \mathrm{C}$ and $5 \% \mathrm{CO}_{2}$ overnight. At $2 \mathrm{~h}$ prior to transfection, the culture medium was replaced with serum-free RPMI-1640 culture medium. To prepare cells for transfection, $5 \mu 1$ siRNA was first diluted in $200 \mu \mathrm{l}$ Opti-MEM (Gibco; Thermo Fisher Scientific, Inc.) without serum. Lipofectamine ${ }^{\mathrm{TM}} 2000$ (Invitrogen; Thermo Fisher Scientific, Inc.) was gently mixed with the diluted siRNA solution (total volume $400 \mu \mathrm{l}$ ) and the samples were incubated at room temperature for $20 \mathrm{~min}$. A total of $200 \mu \mathrm{l}$ of this mixture was added into each well, and the cell culture plate was gently shaken to mix the culture solution. The transfection groups were as follows: Control group, no transfection; vehicle group, transfected with negative control sequences; NISCH-siRNA group, transfected with siRNA sequences targeting the rat $\mathrm{NISCH}$ gene.

Reverse transcription-quantitative polymerase chain reaction $(R T-q P C R)$. Total RNA was isolated using a TRIzol reagent kit (Aidlab Biotechnologies Co., Ltd., Beijing, China) and reverse transcribed into cDNA using the HiScript ${ }^{\circledR}$ Reverse Transcriptase
(RNase H) kit (Vazyme, Piscataway, NJ, USA), according to the manufacturer's protocol. Real-time PCR was performed using the 7900HT Real-Time PCR System (Applied Biosystems; Thermo Fisher Scientific, Inc.), according to manufacturer's protocol. The mRNA expression levels of NISCH were normalized to the endogenous expression of $\beta$-actin. Primers were purchased from Tsingke (Beijing, China). The following primer pairs were used for qPCR analyses: NISCH, forward, 5'-TAT GTTGTGGCACAGAAGATGG-3' and reverse, 5'-TTCAGG CAATGGATAGTGGAT-3'; $\beta$-actin forward, 5'-CACGATGGA GGGGCCGGACTCATC-3' and reverse, 5'-TAAAGACCT CTATGCCAACACAGT-3'. The PCR reaction was performed in a total volume of $20 \mu \mathrm{l}$, consisting of $4 \mu \mathrm{l} \mathrm{cDNA}(5 \mathrm{ng} / \mu \mathrm{l})$, $0.8 \mu \mathrm{l}$ primer mix $(10 \mu \mathrm{M}), 10 \mu \mathrm{l}$ SYBR-Green PCR Master Mix (Vazyme Biotech Co., Ltd.), $0.4 \mu 1$ ROX Reference Dye 2 (50X; ShenZhen Hui Nuo Biotechnology Co., Ltd., Shenzhen, China) and $4.8 \mu \mathrm{l} \mathrm{H}_{2} \mathrm{O}$. Thermal cycling conditions were as follows: $95^{\circ} \mathrm{C}$ for $15 \mathrm{~min}$, followed by 40 cycles at $95^{\circ} \mathrm{C}$ for $15 \mathrm{sec}$, and $60^{\circ} \mathrm{C}$ for $1 \mathrm{~min}$. $\beta$-actin was used as an internal control and the expression levels of target genes were calculated using the $2^{-\Delta \Delta C q}$ method (22).

Western blot analysis. Total protein was extracted from $\mathrm{H}_{2} \mathrm{O}_{2}$-treated cells using lysis buffer (Beyotime Institute of Biotechnology, Shanghai, China) and the samples were incubated on ice for $50 \mathrm{~min}$. Protein concentration was measured using a bicinchoninic acid assay kit (Beyotime Institute of Biotechnology). An equal quantity of protein for each sample was separated via SDS-PAGE on a $12 \%$ gel and then transferred to a polyvinylidene difluoride membrane (EMD Millipore, Billerica, MA, USA). The membrane was blocked with $10 \%$ skim milk in PBS and $0.1 \%$ Tween-20 (pH 7.2) for $2 \mathrm{~h}$ at room temperature and incubated at $4^{\circ} \mathrm{C}$ overnight with an appropriate quantity of the following primary antibodies: Mouse monoclonal anti- $\beta$-actin (dilution, 1:200; cat. no. BM0627; Wuhan Boster Biological Technology, Ltd., Wuhan China), mouse polyclonal anti-NISCH (dilution, 1:500; cat. no. 558262; BD Biosciences), rabbit polyclonal anti-Bcl-2 (dilution, 1:500; cat. no. 12789-1-AP; Wuhan Sanying Biotechnology, Wuhan, China), rabbit polyclonal anti-Bax (dilution, 1:5,000; cat. no. ab32503; Abcam, Cambridge, UK) and rabbit polyclonal anti-caspase-3 (dilution, 1:800; cat. no. 19677-1-AP; Wuhan Sanying Biotechnology). Immunoblots were incubated with the horseradish peroxidase-labeled secondary antibodies goat anti-rabbit Ig (dilution, 1:50,000; cat. no. BA1054) or goat anti-mouse Ig (dilution, 1:50,000, cat. no. BA1051; both Wuhan Boster Biological Technology, Ltd.) for $2 \mathrm{~h}$ at $21^{\circ} \mathrm{C}$, and bands were detected using the Novex ${ }^{\mathrm{TM}}$ ECL Chemiluminescent Substrate Reagent kit (Thermo Fisher Scientific, Inc.). Densitometry analysis was performed using ImageJ software (version 1.48u; National Institutes of Health, Bethesda, MD, USA).

Immunofluorescence analysis. Cells mounted on slides were placed in a culture plate and washed with PBS three times. The cells were then fixed with $4 \%$ paraformaldehyde for 15 min at $4{ }^{\circ} \mathrm{C}$ and incubated with $0.5 \%$ Triton X-100 at room temperature for $20 \mathrm{~min}$. Subsequently, cells were blocked with 5-10\% goat serum (Wuhan Boster Biological Technology, Ltd.) at room temperature for $30 \mathrm{~min}$. Cells were subsequently incubated overnight at $4^{\circ} \mathrm{C}$ with primary antibodies against NISCH 
A
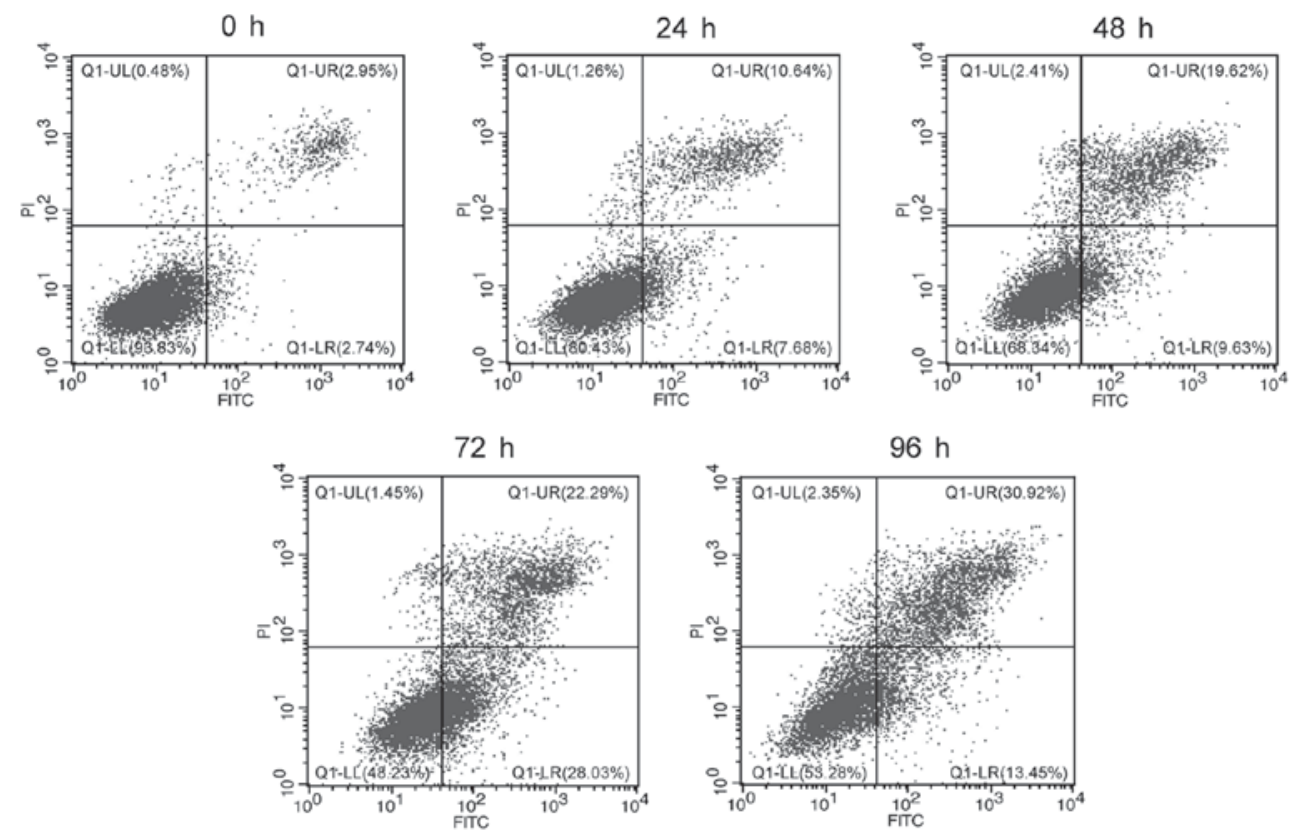

B

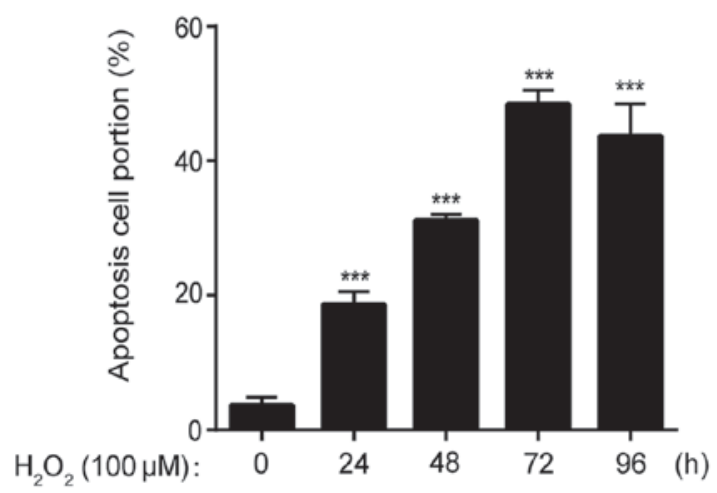

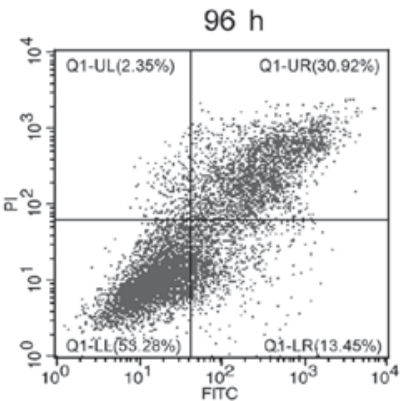

C
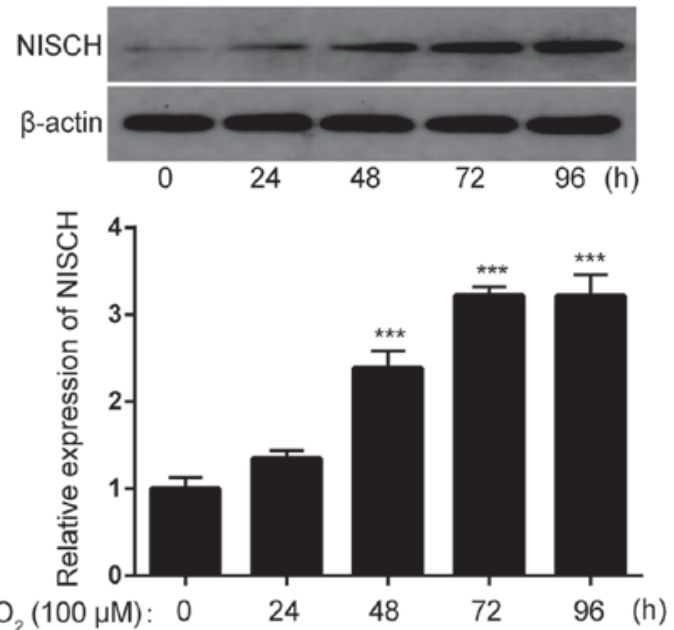

Figure 1. Apoptosis levels and NISCH expression induced by $\mathrm{H}_{2} \mathrm{O}_{2}$ in PC12 cells. (A) Apoptosis levels in PC12 cells following treatment with $100 \mu \mathrm{M} \mathrm{H}_{2} \mathrm{O}_{2}$ for $0,24,48,72$ and $96 \mathrm{~h}$ and (B) quantitative evaluation of the results. (C) The expression of NISCH protein in PC12 cells following treatment with $100 \mu \mathrm{M}$ $\mathrm{H}_{2} \mathrm{O}_{2}$ for $0,24,48,72$ and $96 \mathrm{~h}$. The results are presented as the mean \pm standard error of the mean and are representative of three independent experiments. ${ }_{* * * *} \mathrm{P}<0.001$ vs. 0 h. NISCH, nischarin; PI, propidium iodide; FITC, fluorescein isothiocyanate.

(dilution, 1:50; cat. no. 558262; BD Biosciences), Bcl-2 (dilution, 1:50; cat. no. 12789-1-AP; Wuhan Sanying Biotechnology), Bax (dilution, 1:250; cat. no. ab32503; Abcam) and caspase-3 (dilution, 1:50, cat. no. 19677-1-AP; Wuhan Sanying Biotechnology). Immunofluorescence was generated by incubating samples with the Cy3-conjugated secondary antibodies goat anti-rabbit IgG (dilution, 1:100; cat. no. BA1032) or goat anti-mouse IgG (1:100; cat. no. BA1031; both Wuhan Boster Biological Technology, Ltd.) for $1 \mathrm{~h}$ at $37^{\circ} \mathrm{C}$ in the dark. DAPI $(5 \mu \mathrm{g} / \mathrm{ml})$ was added to counterstain the nuclei, and the slides were incubated for $5 \mathrm{~min}$ at room temperature in the dark before being washed with PBS to remove excess DAPI. Images were obtained using a fluorescence microscope (Olympus BX53; Olympus Corporation, Tokyo, Japan).

Statistical analysis. Statistical analysis was performed using GraphPad 6.0 software (GraphPad Software, Inc., La Jolla, CA, USA). The data are expressed as the mean \pm standard error of the mean and are representative of three independent experiments. Comparisons among multiple groups were performed by one-way analysis of variance followed by a Bonferroni post hoc multiple comparison test. $\mathrm{P}<0.05$ was considered to indicate a statistically significant difference.

\section{Results}

$\mathrm{H}_{2} \mathrm{O}_{2}$-induces cell apoptosis and increases NISCH expression in PC12 cells. Cells were treated with $100 \mu \mathrm{M}$ $\mathrm{H}_{2} \mathrm{O}_{2}$ for $0,24,48,72$ and $96 \mathrm{~h}$, respectively. By staining cells with Annexin V-FITC and PI, the apoptotic rate was analyzed by FACS. The results demonstrated that the proportion of apoptotic cells was significantly increased by $\mathrm{H}_{2} \mathrm{O}_{2}$ treatment of $\mathrm{PC} 12$ cells at all time points (Fig. 1A and B). Furthermore, the expression of NISCH in $\mathrm{PC} 12$ cells was significantly increased by $\mathrm{H}_{2} \mathrm{O}_{2}$ treatment in a time-dependent manner (Fig. 1C). 
A

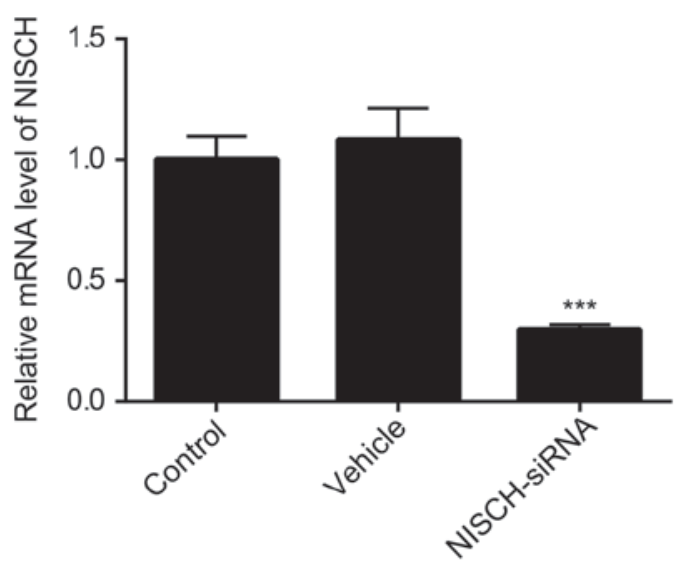

B

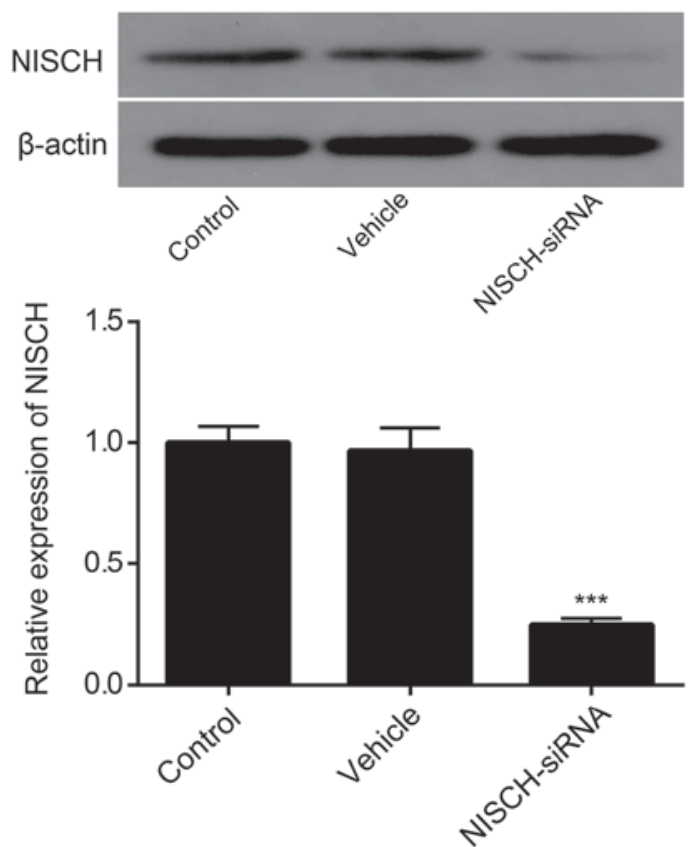

Figure 2. Expression of NISCH following transfection of NISCH-siRNA in PC12 cells. At 48 h following NISCH-siRNA transfection, the (A) mRNA and (B) protein levels of NISCH were significantly decreased. The results are presented as the mean \pm standard error of the mean and are representative of three independent experiments. ${ }^{* * *} \mathrm{P}<0.001$ vs. Vehicle group. NISCH, nischarin; siRNA, small-interfering RNA.
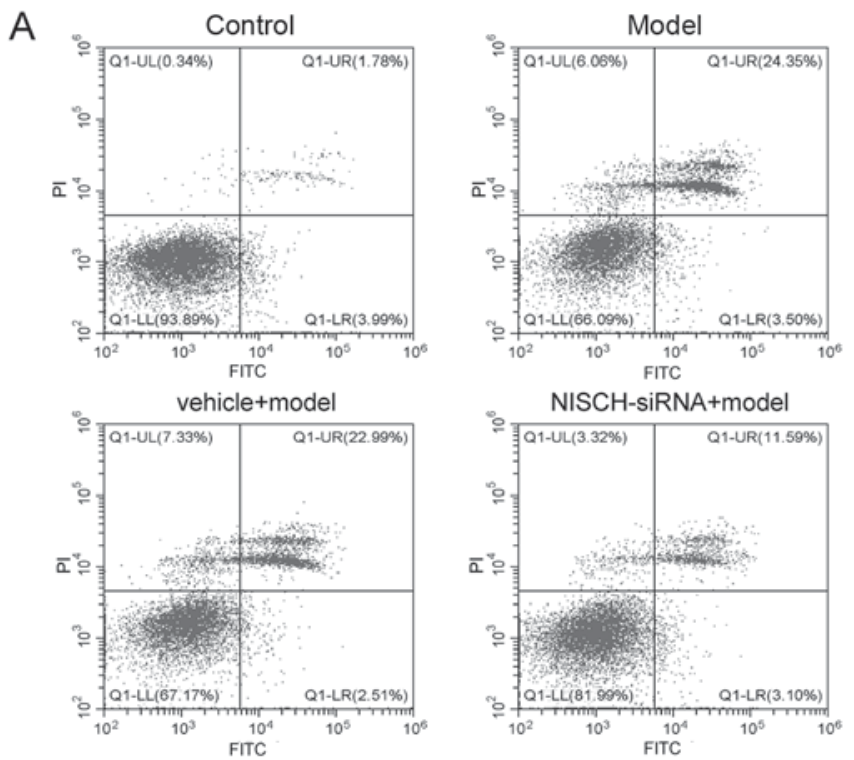

B

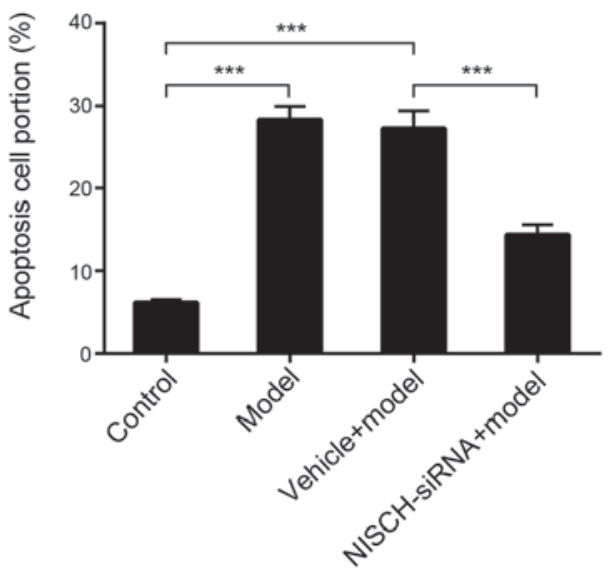

Figure 3. Effects of NISCH downregulation on apoptosis levels induced by $\mathrm{H}_{2} \mathrm{O}_{2}$. (A) Apoptosis levels following treatment with $\mathrm{H}_{2} \mathrm{O}_{2}$ for $48 \mathrm{~h}$ and (B) quantitative evaluation of the results. The results are presented as the mean \pm standard error of the mean and are representative of three independent experiments. ${ }_{* * * *} \mathrm{P}<0.001$ as indicated. NISCH, nischarin; PI, propidium iodide; FITC, fluorescein isothiocyanate; siRNA, small interfering RNA.

NISCH-siRNA reduces NISCH expression in PC12 cells. As demonstrated in Fig. 2A, the level of NISCH mRNA was significantly decreased in PC12 cells at $48 \mathrm{~h}$ following transfection with NISCH-siRNA. Consistent with these results, western blot analysis indicated that the expression of NISCH was reduced in PC12 cells at $48 \mathrm{~h}$ following NISCH-siRNA transfection (Fig. 2B).

NISCH downregulation attenuates $\mathrm{H}_{2} \mathrm{O}_{2}$-induced apoptosis in PC12 cells. As demonstrated in Fig. $3 \mathrm{~A}$ and $\mathrm{B}, \mathrm{H}_{2} \mathrm{O}_{2}$ significantly increased the level of apoptosis in PC12 cells, while NISCH downregulation significantly reduced apoptosis levels at $48 \mathrm{~h}$ following $\mathrm{H}_{2} \mathrm{O}_{2}$ treatment. These results suggested that NISCH may function as a pro-apoptotic protein during $\mathrm{H}_{2} \mathrm{O}_{2}$-induced apoptosis, and downregulation of NISCH may serve a protective role in $\mathrm{H}_{2} \mathrm{O}_{2}$-treated $\mathrm{PC} 12$ cells.

NISCH downregulation alters Bcl-2/Bax signaling induced by $\mathrm{H}_{2} \mathrm{O}_{2}$ in $\mathrm{PC} 12$ cells. The $\mathrm{Bcl}-2 / \mathrm{Bax}$ signaling pathway serves an important role in apoptosis (23). The pro-survival 
A

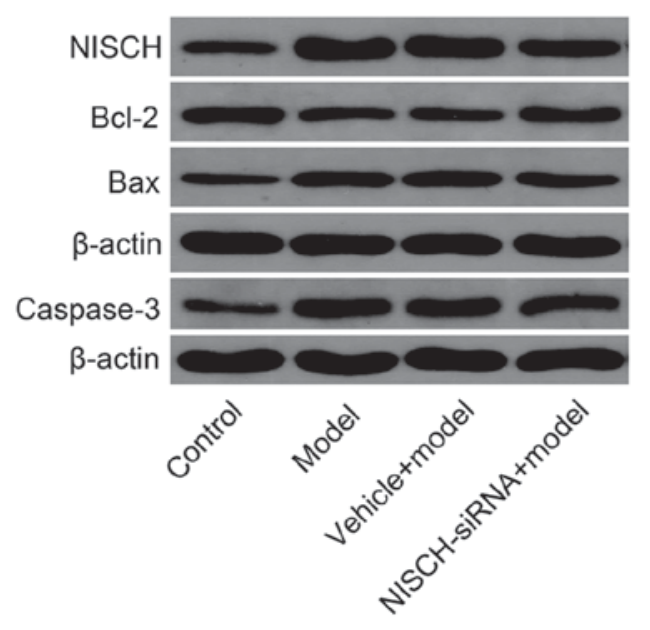

B
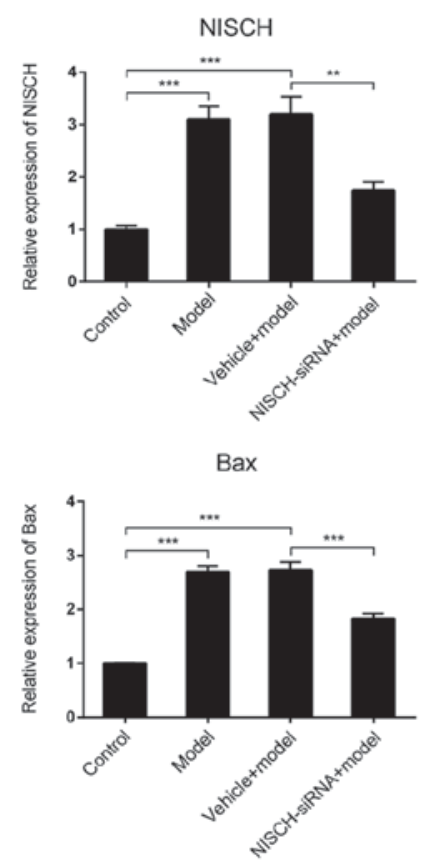
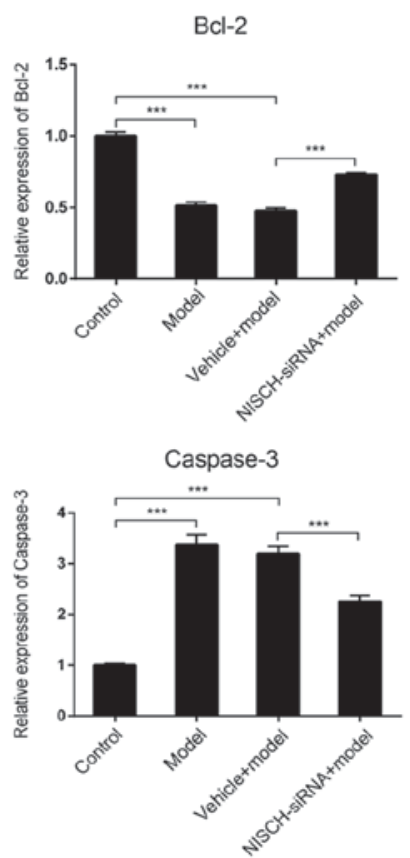

Figure 4. Effects of NISCH downregulation on the Bcl-2/Bax signaling pathway induced by $\mathrm{H}_{2} \mathrm{O}_{2}$. (A) At $48 \mathrm{~h}$ following $\mathrm{H}_{2} \mathrm{O}_{2}$ treatment, the protein expression levels of NISCH, Bcl-2, Bax and caspase-3 in PC12 cells were evaluated by western blotting analysis and (B) the results were semi-quantified. The results are presented as the mean \pm standard error of the mean and are representative of three independent experiments. ${ }^{* *} \mathrm{P}<0.01$ and ${ }^{* * *} \mathrm{P}<0.001$ as indicated. $\mathrm{NISCH}$, nischarin; Bax, Bcl-2-associated X; siRNA, small interfering RNA.

Bcl-2 and pro-apoptotic Bax are the two most extensively studied members of the Bcl-2 family. These proteins function as the primary regulators of the mitochondrial apoptosis signaling pathway (24). Caspase enzymes are crucial effectors of the cell death signaling pathway and are activated by almost all apoptosis-inducing stimuli within neurons and non-neuronal cells (25). Caspase-3 appears to serve a pivotal role in this pathway and has been demonstrated to be necessary for the regulation of development-associated cell death in the brain (25). Therefore, the expression of Bcl-2 and Bax in $\mathrm{PC} 12$ cells at $48 \mathrm{~h}$ following $\mathrm{H}_{2} \mathrm{O}_{2}$ treatment was examined in the present study. As demonstrated in Fig. 4, $\mathrm{H}_{2} \mathrm{O}_{2}$ significantly increased NISCH expression, while NISCH downregulation significantly reduced $\mathrm{H}_{2} \mathrm{O}_{2}$-induced NISCH expression. In addition, Bcl-2 expression was significantly reduced, while Bax and caspase-3 expression levels were significantly increased by $\mathrm{H}_{2} \mathrm{O}_{2}$ treatment (Fig. 4). These $\mathrm{H}_{2} \mathrm{O}_{2}$-induced expression alterations were partially inhibited by NISCH downregulation. The results indicate that NISCH downregulation may protect against the apoptosis of PC12 cells by inhibiting the transduction of $\mathrm{Bcl}-2 / \mathrm{Bax}$ signaling pathways. Immunofluorescence analysis demonstrated the same alternations in NISCH, Bax, Bcl-2 and caspase-3 expression in response to $\mathrm{H}_{2} \mathrm{O}_{2}$ treatment with or without transfection with NSCH-siRNA (Fig. 5).

\section{Discussion}

Oxidative stress and the generation of free radicals, as primary or secondary events, have been implicated in a number of diseases (26). Recent studies have demonstrated that oxidative stress may serve a role in the pathogenesis of SCI $(27,28)$. It has been demonstrated that markers of oxidative stress, such as malondialdehyde, and advanced oxidation protein products are significantly increased in rats with SCI, while antioxidants such as glutathione peroxidase and catalase are significantly decreased (27). In addition, a previous study demonstrated that a significant reduction of the expression of lipid peroxidation factors malondialdehyde may contribute to the reported neuroprotection of the spinal cord from oxidative damage, likely induced by the increased SOD (28). NISCH is reportedly involved in regulating the pathological mechanisms of SCI (21). In the present study, the role of NISCH in oxidative stress-induced apoptosis was investigated using a model of $\mathrm{H}_{2} \mathrm{O}_{2}$-induced oxidative damage in PC12 cells. The results indicated that treatment of cells with $100 \mu \mathrm{M} \mathrm{H}_{2} \mathrm{O}_{2}$ significantly induced apoptosis and increased NISCH expression at different time points. By contrast, NISCH downregulation significantly attenuated apoptosis levels and inhibited the expression of $\mathrm{Bcl}-2 / \mathrm{Bax}$ signaling induced by $\mathrm{H}_{2} \mathrm{O}_{2}$.

Apoptosis is important for the development of neuronal and non-neuronal cells in both the peripheral and central nervous system (29). Aberrant apoptosis contributes to the pathogenesis of a variety of disease states, such as SCI, while inhibition of apoptosis in the pathological state may improve the pathological injury. For instance, it has been demonstrated that treadmill exercise can promote the recovery of motor function by suppressing apoptosis in the injured spinal cord (30), and overexpression of neuroglobin can improve functional recovery by suppressing neuronal apoptosis following SCI (31). In the present study, the expression of NISCH and levels of apoptosis were significantly increased in PC12 cells following treatment with $\mathrm{H}_{2} \mathrm{O}_{2}$ in a time-dependent manner, indicating that NISCH may be involved in $\mathrm{H}_{2} \mathrm{O}_{2}$-induced apoptosis in PC12 cells. 

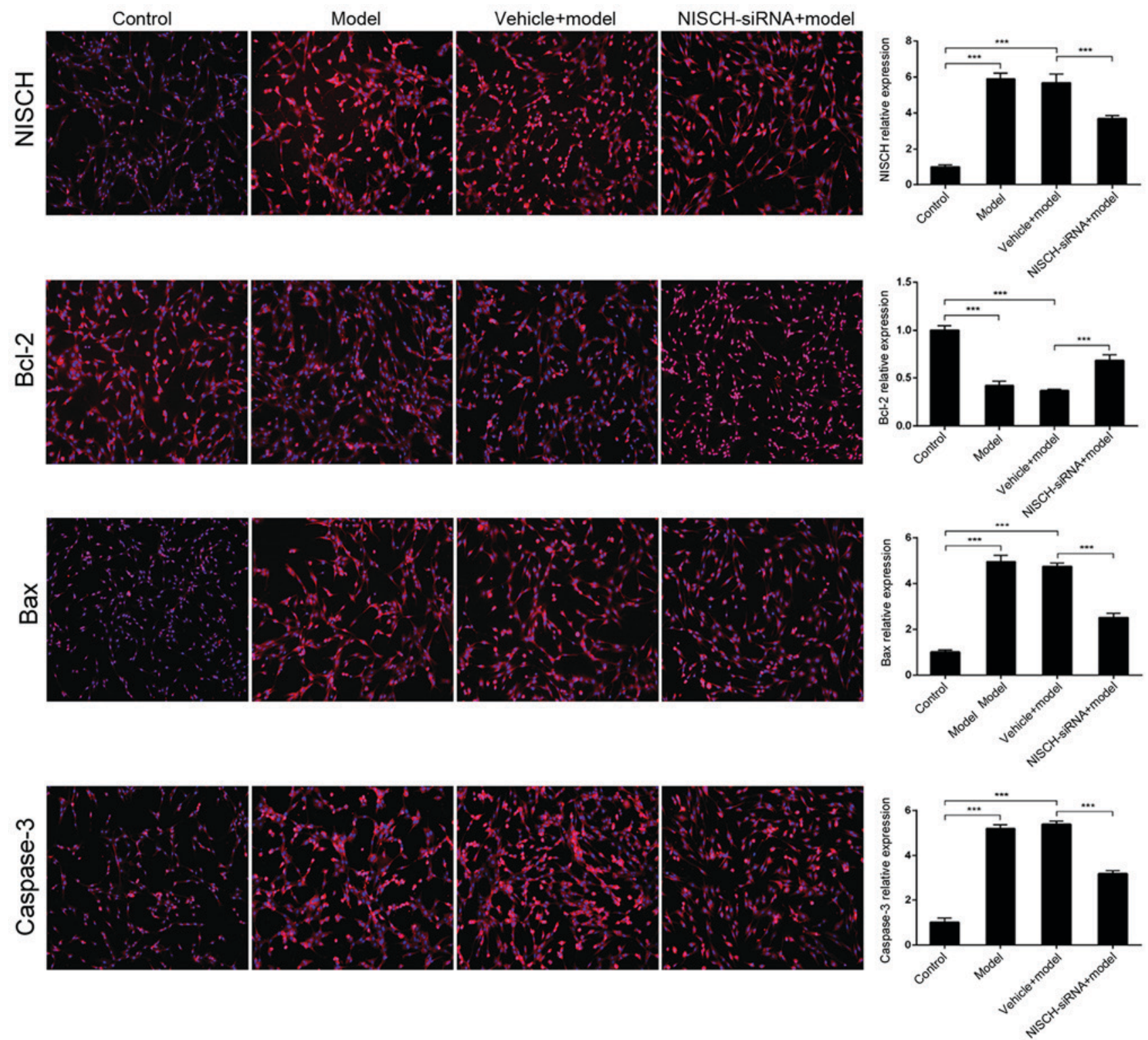

Figure 5. Immunofluorescence analysis of the effects of NISCH downregulation on the Bcl-2/Bax signaling pathway induced by $\mathrm{H}_{2} \mathrm{O}_{2}$. At 48 h following $\mathrm{H}_{2} \mathrm{O}_{2}$ treatment, the expression levels of $\mathrm{NISCH}, \mathrm{Bcl}-2$, Bax and caspase-3 in PC12 cells was analyzed by immunofluorescence staining and quantified. The results are presented as the mean \pm standard error of the mean and are representative of three independent experiments. ${ }^{* * *} \mathrm{P}<0.001$ as indicated. NISCH, nischarin; Bax, Bcl-2-associated X; siRNA, small interfering RNA.

Bcl-2 and Bax are two discrete members of a gene family involved in the regulation of apoptosis. Bcl-2 inhibits cell death in response to various stimuli, while overexpression of Bax exerts a pro-apoptotic effect, and antagonizes the anti-apoptotic activity of Bcl-2 $(32,33)$. Furthermore, the Bcl-2/Bax signaling pathway reportedly participates in the pathogenesis of SCI (34-36). Caspase- 3 is a crucial mediator of apoptosis and a frequently activated cell death protease that catalyzes the specific cleavage of numerous key cellular proteins (37). A previous study demonstrated that caspase-3 is activated following SCI (38), and prevention of caspase-3 activation reduces apoptosis levels (39). In the current study, NISCH downregulation was demonstrated to inhibit the $\mathrm{H}_{2} \mathrm{O}_{2}$-induced reduction in $\mathrm{Bcl}-2$ and increase in Bax expression in $\mathrm{PC} 12$ cells, indicating that NISCH downregulation inhibited transduction of the Bcl-2/Bax signaling pathway. In addition, $\mathrm{NISCH}$ downregulation inhibited the activation of caspase- 3 by $\mathrm{H}_{2} \mathrm{O}_{2}$, which further demonstrated that
NISCH downregulation may attenuate $\mathrm{H}_{2} \mathrm{O}_{2}$-induced apoptosis in $\mathrm{PC} 12$ cells via inhibition of the $\mathrm{Bcl}-2 / \mathrm{Bax}$ apoptotic signaling pathway.

NISCH has been previously identified as a novel protein that selectively binds to the proximal transmembrane region of the integrin $\alpha 5$ subunit cytoplasmic tail (40). Overexpression of the $\alpha 5$ subunit may protect cells against apoptotic stimuli by modulating the expression of the anti-apoptotic protein Bcl-2 via activating the phosphoinositide-3-kinase/Akt signaling pathway (41). NISCH selectively binds to the integrin $\alpha 5$ subunit and negatively regulates the expression of integrin a5 subunit (40). In addition, a previous study demonstrated that overexpression of NISCH may induce apoptosis in human breast cancer cells (20). Therefore, NISCH may exert pro-apoptotic activities by regulating the activity of the Bcl-2/Bax signaling pathway via interaction with the integrin $\alpha 5$ subunit. However, additional apoptosis pathways may be 
involved in the pathological mechanism induced by oxidative stress, which requires further investigation in future studies.

In conclusion, the current study provides evidence for the role of NISCH in oxidative stress-induced apoptosis, and suggests a potential mechanism by which NISCH downregulation attenuates cell apoptosis induced by oxidative stress. The authors of the present study hypothesize that NISCH downregulation may inhibit cell apoptosis by inhibiting transduction of the Bcl-2/Bax signaling pathway. These results may provide a therapeutic candidate for protecting against oxidative stress-induced apoptosis.

\section{Acknowledgements}

Not applicable.

\section{Funding}

The current study was supported by grants from the Guiding Plan of the Natural Science Fund of Liaoning Province (grant no. 201602281) and the Science Studies General Projects in the Department of Education of Liaoning Province (grant no. L2015314).

\section{Availability of data and materials}

All datasets used and/or analyzed during the current study are available from the corresponding author on reasonable request.

\section{Authors' contributions}

ZG, YY, and YG performed the experiments. ZG, HW, and CS collected the data and prepared the manuscript. $\mathrm{ZG}$ and $\mathrm{MH}$ designed the study and analyzed the data. All authors read and approved the final manuscript.

\section{Ethics approval and consent to participate}

Not applicable.

\section{Patient consent for publication}

Not applicable.

\section{Competing interests}

The authors declare that they have no competing interests.

\section{References}

1. Yang YH, Wang Z, Zheng J and Wang R: Protective effects of gallic acid against spinal cord injury-induced oxidative stress. Mol Med Rep 12: 3017-3024, 2015.

2. Liao B, Zhang Y, Sun H, Ma B and Qian J: Ryanodine receptor 2 plays a critical role in spinal cord injury via induction of oxidative stress. Cell Physiol Biochem 38: 1129-1137, 2016.

3. Block ML, Zecca L and Hong JS: Microglia-mediated neurotoxicity: Uncovering the molecular mechanisms. Nat Rev Neurosci 8: 57-69, 2007.

4. Fleming JC, Norenberg MD, Ramsay DA, Dekaban GA, Marcillo AE, Saenz AD, Pasquale-Styles M, Dietrich WD and Weaver LC: The cellular inflammatory response in human spinal cords after injury. Brain 129: 3249-3269, 2006.
5. Zhang N, Yin Y, Xu SJ, Wu YP and Chen WS: Inflammation \& apoptosis in spinal cord injury. Indian J Med Res 135: 287-296, 2012.

6. Lv R, Mao N, Wu J, Lu C, Ding M, Gu X, Wu Y and Shi Z Neuroprotective effect of allicin in a rat model of acute spinal cord injury. Life Sci 143: 114-123, 2015.

7. Khayrullina G, Bermudez S and Byrnes KR: Inhibition of NOX2 reduces locomotor impairment, inflammation, and oxidative stress after spinal cord injury. J Neuroinflammation 12: 172, 2015.

8. Zhao H, Chen S, Gao K, Zhou Z, Wang C, Shen Z, Guo Y, Li Z, Wan Z, Liu C and Mei X: Resveratrol protects against spinal cord injury by activating autophagy and inhibiting apoptosis mediated by the SIRT1/AMPK signaling pathway. Neuroscience 348: 241-251, 2017.

9. Lou J, Lenke LG, Ludwig FJ and O'Brien MF: Apoptosis as a mechanism of neuronal cell death following acute experimental spinal cord injury. Spinal Cord 36: 683-690, 1998.

10. Lu J, Ashwell KW and Waite P: Advances in secondary spinal cord injury: Role of apoptosis. Spine (Phila Pa 1976) 25: 1859-1866, 2000.

11. Chen C, Chen Q, Mao Y, Xu S, Xia C, Shi X, Zhang JH, Yuan H and Sun X: Hydrogen-rich saline protects against spinal cord injury in rats. Neurochem Res 35: 1111-1118, 2010.

12. Bastani NE, Kostovski E, Sakhi AK, Karlsen A, Carlsen MH, Hjeltnes N, Blomhoff R and Iversen P: Reduced antioxidant defense and increased oxidative stress in spinal cord injured patients. Arch Phys Med Rehabil 93: 2223-2228.e2, 2012.

13. Campuzano O, Castillo-Ruiz MM, Acarin L, Gonzalez B and Castellano B: Decreased myeloperoxidase expressing cells in the aged rat brain after excitotoxic damage. Exp Gerontol 46: 723-730, 2011.

14. Bergendi L, Benes L, Duracková Z and Ferencik M: Chemistry, physiology and pathology of free radicals. Life Sci 65: 1865-1874, 1999.

15. Simon HU, Haj-Yehia A and Levi-Schaffer F: Role of reactive oxygen species (ROS) in apoptosis induction. Apoptosis 5: 415-418, 2000.

16. Kang KA, Wang ZH, Zhang R, Piao MJ, Kim KC, Kang SS, Kim YW, Lee J, Park D and Hyun JW: Myricetin protects cells against oxidative stress-induced apoptosis via regulation of PI3K/Akt and MAPK signaling pathways. Int J Mol Sci 11: 4348-4360, 2010

17. Maziveyi M and Alahari SK: Breast cancer tumor suppressors: A special emphasis on novel protein nischarin. Cancer Res 75: 4252-4259, 2015

18. Ding Y, Li Y, Lu L, Zhang R, Zeng L, Wang L and Zhang X: Inhibition of nischarin expression promotes neurite outgrowth through regulation of PAK activity. PLoS One 10: e0144948, 2015.

19. Ding Y, Zhang R, Zhang K, Lv X, Chen Y, Li A, Wang L, Zhang X and Xia Q: Nischarin is differentially expressed in rat brain and regulates neuronal migration. PLoS One 8: e54563, 2013.

20. Chang C, Wei W, Han D, Meng J, Zhu F, Xiao Y, Wu G, Shi X and Zhang L: Expression of Nischarin negatively correlates with estrogen receptor and alters apoptosis, migration and invasion in human breast cancer. Biochem Biophys Res Commun 484: 536-542, 2017.

21. Ding YM, Li YY, Wang C, Huang H, Zheng CC, Huang SH, Xuan Y, Sun XY and Zhang X: Nischarin-siRNA delivered by polyethylenimine-alginate nanoparticles accelerates motor function recovery after spinal cord injury. Neural Regen Res 12: 1687-1694, 2017.

22. Yu S, Liu H and Luo L: Analysis of relative gene expression using different real-time quantitative PCR. Acta Agronomica Sinica, 2007.

23. Wang Q, Zhang L, Yuan X, Ou Y, Zhu X, Cheng Z, Zhang P, Wu X, Meng Y and Zhang L: The relationship between the Bcl-2/Bax proteins and the mitochondria-mediated apoptosis pathway in the differentiation of adipose-derived stromal cells into neurons. PLoS One 11: e0163327, 2016.

24. Wang Y, Wang R, Wang Y, Peng R, Wu Y and Yuan Y: Ginkgo biloba extract mitigates liver fibrosis and apoptosis by regulating p38 MAPK, NF- $\kappa \mathrm{B} / \mathrm{I} \kappa \mathrm{B} \alpha$, and $\mathrm{Bcl}-2 / \mathrm{Bax}$ signaling. Drug Des Devel Ther 9: 6303-6317, 2015.

25. D'Mello SR, Kuan CY, Flavell RA and Rakic P: Caspase-3 is required for apoptosis-associated DNA fragmentation but not for cell death in neurons deprived of potassium. Journal of neuroscience research 59: 24-31, 2015.

26. Fibach E and Rachmilewitz E: The role of oxidative stress in hemolytic anemia. Curr Mol Med 8: 609-619, 2008. 
27. Varija D, Kumar KP, Reddy KP and Reddy VK: Prolonged constriction of sciatic nerve affecting oxidative stressors \& antioxidant enzymes in rat. Indian J Med Res 129: 587-592, 2009.

28. Wang X, Wu X, Liu Q, Kong G, Zhou J, Jiang J, Wu X, Huang Z, $\mathrm{Su}$ W and Zhu Q: Ketogenic metabolism inhibits histone deacetylase (HDAC) and reduces oxidative stress after spinal cord injury in rat. Neuroscience 366: 36-43, 2017.

29. Narayanan V: Apoptosis in development and disease of the nervous system: 1. Naturally occurring cell death in the developing nervous system. Pediatr Neurol 16: 9-13, 1997.

30. Jung SY, Kim DY, Yune TY, Shin DH, Baek SB and Kim CJ: Treadmill exercise reduces spinal cord injury-induced apoptosis by activating the PI3K/Akt pathway in rats. Exp Ther Med 7 : $587-593,2014$

31. Lan WB, Lin JH, Chen XW, Wu CY, Zhong GX, Zhang LQ, Lin WP, Liu WN, Li X and Lin JL: Overexpressing neuroglobin improves functional recovery by inhibiting neuronal apoptosis after spinal cord injury. Brain Res 1562: 100-108, 2014.

32. Chougule M, Patel AR, Sachdeva P, Jackson T and Singh M: Anticancer activity of Noscapine, an opioid alkaloid in combination with Cisplatin in human non-small cell lung cancer. Lung Cancer 71: 271-282, 2011.

33. Ahamed M, Akhtar MJ, Siddiqui MA, Ahmad J, Musarrat J, Al-Khedhairy AA, AlSalhi MS and Alrokayan SA: Oxidative stress mediated apoptosis induced by nickel ferrite nanoparticles in cultured A549 cells. Toxicology 283: 101-108, 2011.

34. Li R, Shang J, Zhou W, Jiang L, Xie D and Tu G: Overexpression of HIPK2 attenuates spinal cord injury in rats by modulating apoptosis, oxidative stress, and inflammation. Biomed Pharmacother 103: 127-134, 2018.
35. Fan L, Wang K and Cheng B: Effects of buyang huanwu decoction on apoptosis of nervous cells and expressions of $\mathrm{Bcl}-2$ and bax in the spinal cord of ischemia-reperfusion injury in rabbits. J Tradit Chin Med 26: 153-156, 2006.

36. Guo SZ, Jiang T and Ren XJ: Influence of neurotrophin-3 on $\mathrm{Bcl}-2$ and Bax expressions in spinal cord injury of rats. J Med Coll PLA 22: 97-100, 2007.

37. Porter AG and Jänicke RU: Emerging roles of caspase-3 in apoptosis. Cell Death Differ 6: 99-104, 1999.

38. Nesic O, Xu GY, McAdoo D, High KW, Hulsebosch C and Perez-Pol R: IL-1 receptor antagonist prevents apoptosis and caspase-3 activation after spinal cord injury. J Neurotrauma 18: 947-956, 2001.

39. Kim YM, Talanian RV and Billiar TR: Nitric oxide inhibits apoptosis by preventing increases in caspase-3-like activity via two distinct mechanisms. J Biol Chem 272: 31138-31148, 1997.

40. Alahari SK and Nasrallah H: A membrane proximal region of the integrin alpha5 subunit is important for its interaction with nischarin. Biochem J 377: 449-457, 2004.

41. Matter ML and Ruoslahti E: A signaling pathway from the alpha5beta1 and alpha(v)beta3 integrins that elevates bcl-2 transcription. J Biol Chem 276: 27757-27763, 2001.

(i) (9) This work is licensed under a Creative Commons cc) Attribution-NonCommercial-NoDerivatives 4.0 International (CC BY-NC-ND 4.0) License. 